\title{
The Role of Social Capital for Amish Entrepreneurs in Pursuing Informal Economic Opportunities
}

Seonhee (“Sunny”) Jeong1

Assistant Professor

Department of Business

Wittenberg University

\begin{abstract}
This study explores the specific types of social relationships that influence initiation into and involvement in informal businesses. In particular, it examines the social capital possessed by Amish entrepreneurs who establish home-based, off-the-books tourism businesses. This paper theoretically refines social capital by identifying three dimensions of social relations: cognitive, reciprocal, and structural. I explore the relationship between social capital and Amish involvement in tourism businesses by using measures of tie strength, expected roles in one's network, structural equivalence of network position, common culture, and religion. The results suggest that neither tie strength nor diversity alone accounts for one's involvement in informal entrepreneurship. Rather, a combination of both strong and diverse ties is positively related to informal business involvement and success. Therefore, researchers of entrepreneurship should give attention to the multiplicity of both network tie strength and diversity.
\end{abstract}

Keywords: entrepreneurship, social network, social capital, informal business, tie strength, diversity of social network, Amish 


\section{The Role of Social Capital for Amish Entrepreneurs in Pursuing Informal Economic Opportunities - Sunny Joeng}

\section{Introduction}

Several studies depict the nature and motives of entrepreneurs operating in the informal economy. For example, Portes and Walton (1981) and Raijman (2001) provide an economic explanation as to why ethnic minority or immigrant communities are involved in the informal sector. With no other options for work or a satisfactory job, they must participate in the informal economy; their economic marginality is widely acknowledged (Gallin 2001). And yet, Williams (2007) finds opportunity-driven entrepreneurs inhabit the informal economy as well. Some entrepreneurs join the informal economy as a choice, seeking to exploit business opportunities. Their voluntary entry into the informal economy is pursued as a source of additional income beyond that necessary to cover normal living expenses. However, few studies have fully explained social capital's role in individuals' informal entrepreneurial involvement, although they recognize the critical role of social capital in business establishment and success.

Entrepreneurship studies have largely addressed how individuals discover and develop opportunities (Venkataraman 1997). An increasing volume of literature about social networks and its positive impact on businesses confirms the benefit of social relationships for knowledge distribution. Greater work productivity benefits from building various forms of partnerships in business (Go and Hedges 1994; Hamel, Doz, and Prahalad 1989). Ramos-Rodríguez, et al. (2010) argues that individuals' capacity to recognize business opportunities is due more to individuals' relationships with other entrepreneurs than to personal knowledge and prior business experience. Other studies also support the case that individuals' access to external knowledge through social networks is fundamental to recognizing new business opportunities (Barringer and Ireland 2007; de Clercq and Arenius 2006; Kingsley and Malecki 2004; Ozgen and Baron 2007; Ramos-Rodríguez, et al. 2010). Large networks (Hills, et al. 1997) and heterogeneous weak ties — ties beyond close friends and relatives (de Clercq and Arenius 2006) - are positively related to the identification and recognition of opportunities (Singh et al., 1999). McGrath (1996) and McAdam (2007) argue that access to a network hub or contact with other entrepreneurs, such as existing successful businesses or business incubators, is a critical source of new opportunity identification. As such, researchers suggest that network location and tie strength are major predictors of identifying successful business opportunities. Hence, social capital predicts small business survival (Korunka et al., 2010). Studies in entrepreneurship also suggest that establishing a social network and building social capital are keys to identifying new entrepreneurial opportunities and ongoing business competitiveness. 
However, almost no research exists on social capital's role in the informal sector. This study helps to fill this gap by examining how social capital influences individuals' pursuit of informal business opportunities related to tourism in the Amish community of Arthur/Arcola in east central Illinois.

This paper defines "informal economy" as the paid production and sale of goods and services which are unregistered by or hidden from state tax records, but which are legal in all other respects (1994; Renoy et al. 2004; Small Business Council 2004; Williams and Winderbank 1998). In order to investigate social capital's role in the informal sector, I first review the literature about entrepreneurship opportunity via social capital and social networks, identifying aspects of social relations that entrepreneurs depend on to identify opportunities and attain resources. Second, previous research identifies three dimensions of social capital. From these dimensions, I develop four hypotheses to test the role of social capital in informal entrepreneurial opportunities. Third, I describe the mixed methods approach used in this study. Results from a quantitative social network survey provide insight into structural dimensions of social capital while qualitative methods-participant observation, indepth interviews, and content analysis-allow me to investigate the cognitive and reciprocal dimensions of social capital. I also describe the Arthur Amish community and its tourism businesses. This paper concludes with findings and discussion.

\section{Theoretical Framework}

To understand the role of social capital on one's initiation into an informal business, I first examine the embededdness of social relationship conditions in business involvement. The theory of social capital is here refined, which then guides this research about relational aspects of entrepreneurs' business pursuits.

\section{A New Model of Social Capital}

Social capital is broadly defined. Foundational definitions have included the following: "the profits which accrue from membership in a group [that] are the basis of the solidarity which makes them possible" (Bourdieu 1985, p. 249), "the number of people who can be expected to provide support and resources” (Boxman, De Grant, and Flap 1991, p. 52), "norms and networks that facilitate collective action” (Woolcock 2001) and "friends, colleagues, and more general contacts through whom you receive opportunities to use financial and human capital” (Burt 1992, p.9). More generally, Schiff (1992, p. 161) defines social capital as "the set of elements of the social structure that affects relations among people and are inputs or arguments of the production and/or utility function.” 


\section{The Role of Social Capital for Amish Entrepreneurs in Pursuing Informal Economic Opportunities - Sunny Joeng}

Thus, much debate surrounds the concept of social capital, its exact components, and its measurement. Several authors note that the literature on social capital is confusing, lacking both terminological precision and theoretical rigor (Lin 2001b; Pilkington 2002; Portes 1998; Portes 2000). Definitions of social capital lack an explanation of the relationship components and contexts that prompt an individual or group of people to exchange or share resources. These relationship components and contexts are treated either as a form or source of social capital (e.g. obligations, trust, or norms), which are then used as explanatory variables of social capital. Coleman (1988) proposed three forms of social capital effective in obtaining benefits: obligations and expectations, information channels, and social norms. Hemingway (1999) also articulated three basic forms of social capital—obligations, expectations, and knowledge - but this categorization confuses forms (i.e. obligations) that activate benefits (i.e. new knowledge) and the benefits themselves.

Portes (1998) referred to activators of social capital as either instrumental sources (reciprocity exchange and enforceable trust) or consummatory sources (value introjections, internalized norm, bounded solidarity, and common fate). In a similar fashion, Pigg and Crank (2004) divided social capital into five sources: networks, resources for action, reciprocity transactions, bounded solidarity, and enforceable trust. Portes (1998) argued that one main confusion in using social capital as an independent explanatory variable arises because relations and abilities to activate resources are not differentiated. Family relationships themselves are not social capital until activated, connecting one to a new job (resource). The trust or norm in a relationship-and not the relationship itself-creates opportunity by activating resources through abilities and forms. Thus, social capital should not be operationalized as relations alone but the forms and activators of relations. The confusion of using relations simply as social capital is common because researchers hastily focus on social capital's advantage as a resource or the benefits extracted from social relationships before trying to define this concept in scientific terms.

This study, therefore, extends the theory of social capital by differentiating the benefits of relations (resources), relations themselves, and components of relations (social capital). The new framework defines social capital in three dimensions: a cognitive dimension, a reciprocal dimension, and a structural dimension. Each dimension may activate latent relations to receive resources. The cognitive dimension includes components shared with others in a relation, including shared identity and identification (Hakansson and Snehota 1995; Merton 1968), norms and sanctions (Putnam 1995), shared language and codes (Arrow 1974), shared narratives (Orr 
Journal of Amish and Plain Anabaptist Studies, Volume 1, Issue 1 (April), 2013

1990), and shared representations of religious, ethnic, and socio-cultural values (Cicourel 1973), all of which encourage reciprocity of resources. Some ethnic groups have developed systems for providing capital to entrepreneurs (Light and Bonacich 1988; Heck, Owen, and Rowe 1995), while others have not (Bates 1994). Shared values and identities (a cognitive dimension of social capital) can motivate group members (relation) to support each other (resource).

The reciprocal dimension bounds individuals together not based on attributes or values but according to assets created and leveraged through relations. Key facets in this cluster are obligations and expectations in relations (Burt 1992; Coleman 1990; Granovetter 1985), roles and status, and trust. For example, the expectations for and roles of college faculty prompt them to make their networks available to students to get a job or internship.

The last dimension of social capital is the structural configuration of ties. Structural configuration entails the network configurations of connection patterns between individuals. It includes the presence or absence of network ties (Scott 2000; Wasserman and Katherine 1994), the structural position of a network (i.e. structural holes), density, connectivity, and hierarchy and tie strength. Jeong (2008) argues that only certain social capital qualities of reciprocal and structural dimensions are related to social network analysis.

In sum, this theoretical framework of social capital distinguishes between activators that obtain a resource embedded in relations and relational ties and resources themselves. For example, friendship (a relation) can help one to find a new job (resource) but the attributes in friendship such as trust, strong ties, and/or shared ethnic values may be the actual activators that help obtain resources. In this case, neither friendship nor a new job leveraged through a relation is social capital. Each social capital dimension should be operationalized to examine what activates relations to gain resources. More importantly, each dimension might explain the research questions to a different degree. This paper proposes several hypotheses of entrepreneurship to test the utility of the proposed social capital theoretical framework. In so doing, I confront the issue of measurement, appropriating a measurement of social capital and identifying the theoretical rationales to do so. As Borgatti, et al. (1998), Lin (2001a) and Castle (2002) note, without embedding the concept of social capital in theories, social capital would fade away as an intellectual enterprise that generates testable hypotheses through either qualitatively based or quantitatively derived data. 


\section{The Role of Social Capital for Amish Entrepreneurs in Pursuing Informal Economic Opportunities - Sunny Joeng}

\section{Hypotheses}

This study places social capital in a theoretical context, where social theories guide each dimension of social capital. I develop hypotheses to test these theoretical relationships, specifically in the context of informal business opportunities.

\section{The Cognitive Dimension of Social Capital}

The cognitive dimension of social capital is articulated by homophily theory (Marsden 1988; Marsden and Campbell 1984), which explains people’s tendency to interact with similar others. Actors have their closest ties to members who are perceived to be similar. Homophilous relations form in contexts of ethnicity, religion, language, education, occupation, gender, and geographic propinquity. Some (Feld 1984; Marx and Spray 1972) argue that people are more likely to activate positive ties among people with similar backgrounds, giving emergency help, loaning money, giving trusted advice, or providing therapeutic counseling. Others (Marsden 1987; Marsden 1988) argue that homophily means less exposure to a wider range of ideas and resources, so is negatively related to entrepreneurial opportunity recognition. Economic opportunities are more likely to come from heterogeneous social ties while homogeneous social ties come in handy for more emergent situations. This paper brings particular attention to the relationship between religious and cultural similarity as explored in the shared language and values of the Amish and their involvement in informal entrepreneurial opportunities.

Hypothesis 1: According to the homophily theory, homogeneous ties are positively associated with involvement in informal entrepreneurship.

\section{The Reciprocal Dimension of Social Capital: Expected Roles in the Creation of Informal Business Opportunities}

Social role theory explains that social statuses and the roles embedded therein influence social actions. According to Michener (2004), role theory poses the following: (1) people spend much of their lives in groups; (2) within these groups, people often take distinct positions; and (3) each position is a role, with a whole set of functions that are molded by the expectations of others. Role norms are an expected set of behaviors for people holding a role and status (Bidddle and Thomas 1966). Individuals who play an active role in the business development of a small community (embracing it as part of their overall role) may be more likely to create informal business opportunities and pursue these opportunities. Community networks may be 
crucial to becoming acquainted with new business opportunities. In terms of the network perspective, Cobb (1988), in her research about the involvement of business leaders in local tourism development, found that business leaders perceived as more central in a community's social structure had a greater level of active participation in influencing decisions about community tourism planning. Influential business leaders who take on an active role in a community have extensive communication networks and receive more customer referrals than others. Accordingly, ties with those perceived to be highly influential in community businesses can be positively associated with new business opportunity identification and the actual pursuance of the business.

Hypothesis 2: According to the role theory, the more influential role one is expected to have in the community, the more likely the person is to be involved in an informal business opportunities.

\section{The Structural Dimension of Social Capital: The Influence of Tie Strength and Structural Equivalence}

Contagion theory (Burt 1978) states that the structural dimension of social capital facilitates involvement in informal business opportunities since attitudes and behaviors are influenced by closeness to others to whom one is directly connected (contagion by cohesion). What about the strength of connections? Do businesses that have strong family social networks have higher profits, faster growth, and higher survival rates than those businesses with weak network ties? Coleman (1988) framed social capital as inherent in strong social relations. His examples showed the benefit of strong ties when running a family business among diamond merchants (family and religious ties) and among merchants in an Egyptian market (family ties and business longevity).

Hypothesis 3: According to the contagion by cohesion theory, strong network ties are positively associated with involvement in informal entrepreneurship.

Another structural dimension of social capital is guided by structural equivalence theory. Structural equivalence refers to actors who have the same ties to the same people even if they are not tied to each other. Contagion theory by structural equivalence suggests that attitudes and behaviors are similarly influenced by others when both actors have the same relations to others. Two actors reachable by a common set of other actors (structurally equivalent) are pressured by these others to think and behave in similar ways (Friedkin 1998) . 
The Role of Social Capital for Amish Entrepreneurs in Pursuing Informal Economic Opportunities - Sunny Joeng

Hypothesis 4: Individuals who are structurally equivalent are likely to have similar degrees of involvement in informal entrepreneurship.

Guided by social theories, these three dimensions of social capital - the cognitive, reciprocal, and structural dimensions - serve as the foundation for my research questions and four hypotheses, which are summarized in Table 1.

Table 1: Theoretical Framework

\begin{tabular}{|l|l|l|}
\hline $\begin{array}{c}\text { Dimension of } \\
\text { Social Capital }\end{array}$ & Directing Social Theory & \multicolumn{1}{c|}{ Variables } \\
\hline $\begin{array}{l}\text { I. Cognitive } \\
\text { Dimension }\end{array}$ & $\begin{array}{l}\bullet \text { Social exchange theory } \\
\bullet \text { Contagion (by } \\
\text { cohesion) theory } \\
\bullet \text { Collective action theory }\end{array}$ & $\begin{array}{l}\text {-Shared codes, language, norms, } \\
\text { religion, ethnicity }\end{array}$ \\
\hline $\begin{array}{l}\text { II. Reciprocal } \\
\text { Dimension }\end{array}$ & $\bullet$ Social role theory & $\begin{array}{l}\bullet \text { Reputation } \\
\text {-which were most influential in } \\
\text { the formation of the development } \\
\text { plan. } \\
\text { - which should be part of decision } \\
\text { making } \\
\text {-Trust } \\
\text {-Benevolence-based trust (i.e. he } \\
\text { or she cared what happened to } \\
\text { me) } \\
\text {-Competence-based trust (i.e. } \\
\text { belief in one's competence and } \\
\text { preparation) }\end{array}$ \\
\hline III. Structural \\
Dimension & $\begin{array}{l}\bullet \text { Contagion by cohesion } \\
\text { theory } \\
\bullet \text { Contagion by structural } \\
\text { equivalence theory }\end{array}$ & $\begin{array}{l}\bullet \text { Tie Strength Degree } \\
\text {-Structural hole } \\
\text {-Network roles and positions } \\
\text {-Network structural equivalence }\end{array}$ \\
& & \\
\hline
\end{tabular}


Journal of Amish and Plain Anabaptist Studies, Volume 1, Issue 1 (April), 2013

\section{Methods}

In this study, a mix of quantitative and qualitative methods are implemented sequentially, in order to allow earlier methods to guide the development of later methods, and in order to triangulate findings (Greene, Benjamin, and Goodyear 2001; Greene, Caracelli, and Graham 1989; Reardon 1998). Triangulation seeks the convergence, corroboration, and correspondence of results from the different methods to increase validity or credibility and reduce known bias. The mixed method approach allows the framework proposed in this study to use a stronger and more defensible tool. By so doing, research using this method achieves dialectical discovery of enhanced, reframed, or new understandings.

According to Morrill and Fine (1997), most qualitative studies are generally not about "attitude," "norms," "roles," or other abstract concepts, but more about what people actually say and do in specific places and institutions, including their interactions with others over time-in other words, how social activities (relationships, events, cultures, organizations, and movements) occur or develop in a social and temporal context. My engagement with the Amish community, my relationships with the research subjects, and the impact of the findings directed this study towards the constructivist approach of grounded theory (Charmaz 2003).

Participant observation and interviews are used first for sampling. Next, I designed a social network questionnaire with the list of names identified during interviews. I then analyzed the informal business network structure to determine the relation between social capital and new business involvement. With this design, one set of findings characteristically illustrates, enhances, helps to explain, or refines the other set of findings (Mark, Feller, and Button 1997).

Social network analysis is a set of methods for mapping the real, often simultaneous, interpersonal relationships and interactions among a set of social actors; from it, we can analyze how structural regularities influence actors' behaviors (Barnes 1972; Bott 1971; Leinhardt 1977; Marsden and Lin 1982; Rogers and Kincaid 1981; Wellman and Berkowitz 1988). Corman (1996) defined social network analysis as a way of conceptualizing, describing, and modeling social collectivities as sets of entities (people and/or groups) linked to one another by specific characteristics like perceptions, attitudes, behaviors, and traits. Simply put, social relationships are the basic units of analysis and the network is "a specific set of linkages among a defined set of people” (Mitchell 1969, p. 2). 


\section{The Role of Social Capital for Amish Entrepreneurs in Pursuing Informal Economic Opportunities - Sunny Joeng}

\section{Research Site and Data}

When it comes to the location of entrepreneurship, there is some evidence suggesting that rural areas may be more successful than urban areas in the rate at which they generate entrepreneurs (Lin, Buss, and Popovich 1990). Social relationships in rural communities usually merge with commerce (Miller 2001), which plays a critical role in opportunity identification, development, and successful management and survival of small businesses (Granovetter 1985). Close friends and supportive family members in small towns are critical resources for one to initiate, manage, and survive a small business. I have chosen the Arthur, Illinois, Amish community as the research site. Tourism income is increasing rapidly here. Over three decades ago, Buck’s (1978; 1979) research of the large Lancaster, Pennsylvania, Amish community reported that over the previous 35-year history of tourist enterprises in “Amish Country," yearly visitation had increased to four million dollars and the yearly gross tourist-related economic production was already in excess of \$175 million. As such, tourism’s role has great potential to impact the local economies of Amish communities, both large and small (Boynton 1986).

Since land prices in the Arthur area prevent younger Amish from entering farming, they have increasingly turned to woodworking, carpentry, and other work. Today, it is estimated that about one-third of the Arthur area Amish still farm, another one-third supplement farm income with part time or seasonal employment, and the remainder rely on full time cottage industries and crafts or have full time employment with area firms. Information provided by the Arthur Welcome Center shows that approximately 225 rural businesses in the Arthur area are owned and operated by Amish families. ${ }^{2}$ Due to the increasing economic dependence on tourism, this area is defined as a tourism community.

To investigate new business involvement and social capital, I analyze the relational structure of community members by conducting in-depth interviews. The Amish, Mennonites, and "English"3 in this area are a small, tightly-knit, but relatively diverse social group. Small groups of Amish, Mennonite, and English interviewees represent interactions and collaborations. Some interviewees live in Arthur and others live in different towns, but they are all involved in the private sector of the tourism industry, working as tour operators, tour program participants, or other tour-oriented positions. Collaborative dynamics and relations provided more meaningful insight because of the diversity of group characteristics. In addition, the strong social ties in the Amish community facilitate the feasibility of quantitatively investigating social 
relations. I identified and interviewed between 20 and 30 stakeholders by their current and past participation in tour programs.

The Arthur Amish community is composed of around 1,810 members and 2,028 unbaptized children and adolescents of Amish families, making it the eighth largest Amish settlement (Donnermeyer, Anderson, and Cooksey 2012). There has been little research on small business and social networks in this Amish community. Kraybill, Nolt, and Wesner (2011) interviewed 161 Amish business owners over a ten year period and utilized five forms of socio-cultural capital that explains the success of Amish entrepreneurs. They present a dichotomy between ethnic and non-ethnic networks of social capital, contrasting ethnic network strong ties to non-ethnic network weak ties. The unit of analysis in this regard is a community instead of an individual, which makes it impossible to compare tie strength between individuals in one community. Individuals gain different benefits due to strong and weak ties with others. Also, this framework excludes the combined network effect of strong nonethnic network ties or weak ethnic ties among individuals. On the other hand, Hawley and Hamilton (1996) located Amish business strategies in the cultural context of entrepreneurship. They highlighted the Amish's responsibility and measure of success to sustain Amish culture through the cooperative culture of business networks. Competitive advantage of local and nationwide Amish networks is mentioned under the cultural context of cooperation among Amish businesses. Both studies examined network aspects of Amish entrepreneurship in a preliminary manner and this study will further expand our understanding on relational aspects of Amish entrepreneurship.

In addition, this research considers community participation and engagement in informal tourism business opportunities in Arthur, Illinois, making this study distinct from research conducted in other Amish communities or other tourism communities in general. Regardless of the uniqueness of the site, though, this study can be applied to any other small rural community with appropriate cultural, local, and community resources to attract tourists

The Arthur Amish community is an offshoot from the Lancaster, Pennsylvania, Amish settlement. The Arthur Amish settled on the border between three counties: the southwest corner of Douglas County, the northwest corner of Coles County, and the east side of Moultrie County. The majority of Amish residents live around Arthur, giving it the settlement's name. The main business street (Vine) in Arthur divides Moultrie and Douglas County. The east-west extent of the Amish settlement is twenty-one miles and the north-south, nineteen miles, with an area of three hundred seventy-five square miles. 


\section{The Role of Social Capital for Amish Entrepreneurs in Pursuing Informal Economic Opportunities - Sunny Joeng}

According to the Illinois Amish Interpretive Center (2006), the first Amish settlers came in 1864, nine years before Arthur became an incorporated village. In the late 1930s, a Mennonite minister came to Arthur and soon there were Amish people converting to this more modern religion. While the Mennonites did share the basic beliefs of the Amish, they could have automobile ownership, telephones in the home, and electricity from power lines. The Arthur Mennonites are by far the most liberal, but even the other conservative churches are allowed most of the modern conveniences, such as cars, telephones, and electricity. This community now consists of around 3,900 Old Order Amish adherents organized into 26 church districts. Each district contains about 20 families. A bishop presides over each district and two ministers serve each congregation.

Data for grounded theory can come from various sources. In this study, data collection included interviews, observations, hard documents, Amish tourism video clips, newspapers, magazines, letters, emails, and books - anything that could help answer the research questions. Each source can be coded in the same way as interviews and observations (Glaser and Strauss 1967). Grounded theory has specific procedures for data collection and analysis. Distinct from other qualitative methods, grounded theory dictates that data emerge from the experiences of participants (Taylor and Bogdan 1998). The analysis begins as soon as the first data are collected (Strauss and Corbin 1990) so that previous findings guide the next research method design and analysis. All seemingly relevant issues must be incorporated into the next set of interviews, observations, and methods. This process is the basis for the effectiveness of the grounded theory approach. Repeating concepts present in interviews, documents, and observations in one form or another are the basic units of analysis. The researcher groups these concepts to develop theory. The research process itself guides the researcher toward examining all of the possible avenues of understanding. This is why the research method is one of discovery and one that grounds a theory in reality (Glaser and Strauss 1967).

Finally, narrative analysis for the secondary data was used. Social science is a set of socially constructed understandings built from discourse structures. These discourse structures have narrative properties that should be analyzed to understand how the structures of the discourses themselves create local meanings, become hegemonic, or seek to persuade.

Social network data were collected through interviews to increase data accuracy. Although each actor may accurately diagram the social links of the five or six closest 
relations, their assumptions about ties outside their immediate circle are usually inaccurate. Therefore, I examined their perceptions of the social structure and each others' perceived roles with a qualitative research method: an explanation about people's roles in informal tourism programs refreshes their memory of work-related relationships. Also, later interview survey sessions sometimes corrected a previous answer given by others. For example, some links between individuals cannot be explained by direct questions about relations such as friends, family, church group, neighborhood, and business. Many people in the Amish community are linked to each other as an indirect relation of acquaintance such as my father's closest friend's son, my wife's cousin, a close friend of my mom, etc., which cannot be simply listed as a friend or family relation. The qualitative social network survey method helps control the consistency of findings. The data collected are more consistently interpreted by others with the help of the researcher.

The people involved in tour programs included twelve English and 10 Amish respondents. Fourteen were women and eight were men. All respondents lived or had very recently lived in the Arthur Amish settlement. With such a small number, conducting in-person interviews with each family or individual was feasible. Interviews lasted from one to two hours. Names of individuals involved in Amish tour programs were accumulated while the interviews proceeded. At the point when no new names were mentioned, the social network survey list of people was finalized. In addition to the 22 people involved in tour programs, three other private Amish tour programs exist: Amish Country Marketing \& Tours, Rockhome Garden, and Stella Tours. All main operators, owners, and directors were included on the actor list as well. A total of 28 people were interviewed between September and November 2007. The list of 22 people, who responded to both informational and network interviews, was generated after the first phase of interview with six people.

\section{Quantitative Measures}

Social network analysis (hypothesis 1): I analyzed the relationship between social capital and informal business involvement using the three dimensions of social capital: relational, structural, and cognitive. Social network analysis is used to analyze the reciprocal and structural dimensions while qualitative methods analyze the cognitive dimension.

\section{The relational dimension of social capital, role expectation (hypothesis 2):} The following two questions examined role expectations and its relation to informal business involvement: "(1) Please identify those of the selected individuals, including yourself, who provided you with information/advice in regard to tourism development 


\section{The Role of Social Capital for Amish Entrepreneurs in Pursuing Informal Economic Opportunities - Sunny Joeng}

opportunities. There is no limitation on the number of people that may be nominated" (expected advisor role); and "(2) We would like you to pick those individuals who were in your opinion most influential in the formation of this informal business plan" (expected decision making role in a community for this business opportunity).

The structural dimension of social capital, tie strength (hypothesis 3): Tie strength is a quantifiable property characterizing the link between actors. By definition, tie strength is a "combination of the amount of time, the emotional intensity, the intimacy (mutual confiding), and reciprocal services which characterize the tie" (Granovetter 1973, p.1361). There are indicators and predictors that measure tie strength. Indicators are actual components of tie-strength (closeness, duration and frequency, breadth of topics, and mutual confiding) whereas contextual contingencies are predictors (neighborhood, affiliation, similar socio-economic status, workplace, and occupational prestige). Predictors are related to tie-strength, but not components of it.

I measured tie strength by closeness of relation (weighing work and friendship relationships differently) and frequency of communication in both relations. The work network consists of frequency of work relations, including in-person meetings, emails, and phone conversations. Strength of relational ties was measured by asking the following two questions with a seven-point Likert scale. "Prior to being involved in informal tourism programs, (1) For each of the people you know on this list, how long have you known them? (2) How often have you worked with them? Please estimate face to face meetings, emails, and telephone conversations. (3) How often have you socialized with them? For example, how often have you gone for coffee, had nonwork conversations, emails for chatting, or attended a social gathering with them?”

\section{The structural dimension of social capital, structural equivalence} (hypothesis 4): The structural dimension of social capital is assessed by measures of a sociocentric network dataset, as opposed to a network that is more egocentric or individualistic. Hence, the last two questions used to measure tie strength on this basis: work network and social network. Closeness centrality and betweenness centrality ${ }^{4}$ for each network were measured. Sociocentric indicators help to determine the extent to which social capital is related to informal business involvement.

Dependent (outcome) variable: Individuals' involvement in informal tourism business opportunities was measured by indicating the level of agreement with the following questions using the seven-point Likert scale: "In terms of the involvement, 
Journal of Amish and Plain Anabaptist Studies, Volume 1, Issue 1 (April), 2013

the level of current and future involvement (1=very active, 3=somewhat active, $5=$ not very active, $7=$ not at all active) was measured."

\section{Results}

\section{The Cognitive Dimension of Social Capital: The Influence of Religion and Culture}

A bonding effect is evident in the Amish community. The Amish frequently help family, neighborhood, and church members. The church's involvement in Amish-owned businesses was unique and systematic, evident in their exclusive support for one another. This is illustrated by a report from Lovina Eicher ("The Amish Cook”), who is an Amish mother of eight from a community in southern Michigan and writes a column for over 100 newspapers about Amish family and community life:

On Saturday our neighbors are having a “doughnut drive” to help a family in our church with hospital bills. Then the following Saturday a family is doing a "sub drive" to help another family. For the sub drive a lot of women will go the day before and help cut up vegetables. At 3:30 a.m. the next morning people will gather to help put the sub sandwiches together. They will then have drivers to go deliver them in nearby Amish communities...it is nice the way everyone helps one another out around here (Lovina Eicher, Oct. 1. 2007 "Daughter learns about food processing, sewing clothes is next” Retrieved October 2, 2007 from www.Jg-tc.com, local newspaper B2).

One Amish wife who hosted visitors for meals in her home used the word "Amish" to promote the business (which is not allowed). Her church found out, but because of her desperate economic condition, was granted exemption. In this case, Amish rules and norms are flexible and their enforcement depends on each district's culture and leadership. Many times, churches are actively involved in helping young members start their own businesses and houses.

Twenty to thirty years ago when I worked at the local bank, I worked with Amish churches...the church has a trustee or financial adviser we can call... and they lend 1-2 acre to young families to build their own houses...Also, one time there was a guy (mentally disabled) who had a lot of debts to the bank and he met with a financial advisor in church... What the church did was they took out the management part for all his income. He made harness and leather... His income directly went 


\section{The Role of Social Capital for Amish Entrepreneurs in Pursuing Informal Economic Opportunities - Sunny Joeng}

to the church and the church [Amish financial committee] paid off certain amounts of the debt regularly...Actually, he survived after all. (Respondent 4, English, Male, October 1, 2007)

The board is composed of less than three men in church once a church member is in trouble. Whether the deacon or bishop or someone they like to ask for help will be chosen on the board...then they will be helping...Also, there is the $\mathrm{ABC}$ group [nonprofit organization run by the Amish] who help young Amish people to start their new lives...they provide loans with very low interest. Currently 10-13 millions are out there to help. (Respondent 11, Amish farmer, Male, October 2, 2007)

Despite the beneficial roles of Amish churches, the churches' involvement was interpreted sometimes negatively by the English community.

One Amish family made lots of money by serving tourists and the church got out to warn this family for their being wealthy...Although few, the Amish became Mennonite when their wealth became much more than they should have. (Respondent 5, English, Female, October 19, 2007)

However, this case could not be confirmed in the Amish interviews. One wealthy Amishman said this:

[We make our money] all on our own and the church does not say anything about it... The Amish separate church from business.

(Respondent 12, Amish, Male, October 2, 2007)

Regarding collaboration in tourism businesses and economic opportunities, the Amish are not harnessing their religious / cultural homophily, contrary to my expectations. When I showed interviewees the list of those involved in tourism businesses, most did not acknowledge each other's involvement. Sometimes, they perceived each other as competitors.

I did not know that they were all serving meals too...so they are all my competitors. (Respondent 13, Amish, Male, July 24, 2007)

They like to be secret about their good businesses (Respondent 12, Amish, Male, October 2, 2007)

Sunny: Do you like to meet all together? 
Journal of Amish and Plain Anabaptist Studies, Volume 1, Issue 1 (April), 2013

Respondent 14: Well...for what?

Sunny: Discussing about different things...how to improve services better, who is doing what better than others, how to learn from each other, how to deal with visitors etc.?

Respondent 14: But people might like to be secret about what they are doing good and do not like to share. (Amish, Female, July 25, 2007)

The tightly knit Amish community's positive role in managing small businesses may be a myth or else social capital works only when not conflicting with one's economic interests. English people in the Arthur community tend to think that social influence or gossip about a successful business story will spur additional Amish involvement in similar businesses. However, the Amish do not share their business stories and none of the interviewees indicated their business was initiated by another Amish person's successful example.

Most Amish tourism business participants became involved because of the Amish Interpretive Center director's relations with Amish families. Crossing cultural boundaries to extend ties was significant in Amish business establishment. However, it is noteworthy that these extensive cross-boundary ties are not weak ties but strong ties of friendship, familial relation, or work ties with frequent interactions. They are either neighbors or linked indirectly by distant families or friends.

Oh yah...Setting up meal providers is based on my personal relations. (Respondent 1, English, Male, July 20, 2007)

I went out one day to my neighborhood [the Amish family] and asked him if he has an interest in woodworking tour or serving meals at his home. He said “I would ask my wife.” Right after that day, he came to me saying he would like to do that. That's how they got into it.

(Respondent 2, English, Female, September 11, 2007)

And basically how that came about, I was really good friends with her daughter...she's Amish. And Carolyn, her mom, was asking me what do I do at the Center... what does that entail. And I told her that we schedule meals and tours and the museum. And she said, "You know, I think I'd be interested in doing that.” So I came to work and told the director that, you know, there was somebody Amish interested in doing them. I didn't 


\section{The Role of Social Capital for Amish Entrepreneurs in Pursuing Informal Economic Opportunities - Sunny Joeng}

know if the Center needed anybody. So it just kind of happens...

(Respondent 3, English, Female, July 17, 2007)

As is often the case for discovering employment, personal contacts and networks are effective ways to find new economic opportunities. The previous owner of Rockhome Garden (one of the most popular tourism destination in this area) explained that some of the neighborhood Amish came along and worked for him once in a while. Due to the length of acquaintance with neighboring Amish families, he could ask them to work for the Rockhome Garden.

One Amish guy I have known for a long time drives buggy on Saturday and he picks days he can work for this. (Respondent 7, English, Male, April 17, 2004)

Sunny: In terms of the Amish environment, do you think that the Amish come and seek the opportunity or do you actually find those people who might have interest in it?

Respondent 1: Well, it's hard to explain it. One of the biggest occupations in the area is woodworking. And I'm not sure if anybody has explained to you the relationship that the businesses around here have. There's about 47 woodworking families in the area. And the vast majority of them sell to what's known as the Simply Amish brand. If you're out on Springfield Road, you see that huge warehouse out there called J\&M Representatives. Well, J\&M owns the Simply Amish brand. And so then J\&M Representatives, Simply Amish...they sell nationally. They distribute our Amish people's furniture nationally. A lot of the woodworking businesses only sell wholesale. They don't sell retail. Yeah. But we have several places in the area that sell Simply Amish. Country Charm out here...Y Yoder's Homestead Shop and then some places in Arthur, too. So the Amish... because I guess some of them do sell retail and try that kind of thing...but a lot of the Amish...it's kind of the same idea with the Amish meal providers not wanting to deal with the public. So if they can just sell to J\&M and J\&M sell, then it's a lot easier for them. And they can rely on...because J\&M has really built their business up, they can rely on the orders. And so it's a win-win relationship. (English, Male, July 25, 2007) 
Those with extensive ties between different communities are more likely to get invited to informal business opportunities than ones with ties only among people in their own community. Therefore, the first hypothesis, that homogeneous ties have a positive impact on informal business involvement, is not supported.

\section{The Relational Dimension of Social Capital}

To test the second hypothesis of the role theory, I created an advice role expectation network and a decision making expectation network from my data. The former consists of linkages whereby individuals obtain useful knowledge and information. Of the 22 listed individuals, participants identified those who provided information and advice about informal tourism business opportunities. In-degree centrality was used to measure the advice role expectations. As an example of indegree centrality, if three people each say so-and-so gave them advice and information, then so-and-so's in-degree centrality is three. In the same vein, I computed in-degree centrality measures for the decision making role expectation network. Respondents selected individuals who they felt were the most influential in the formation of the development plan and who should be involved in decisionmaking and planning. To test the second hypothesis, the two role expectation matrices were summed into one aggregate measure, generating an overall role expectation. Descriptive statistics and Pearson correlations among these variables are summarized in Table 2 followed by the results presented in Table 3.

\section{Table 2: Descriptive Statistics and Correlations}

\begin{tabular}{|c|c|c|c|c|c|}
\hline Variables & 1 & 2 & 3 & 4 & 5 \\
\hline 1. Involvement & - & .53 & .24 & -.23 & -.29 \\
\hline 2. Role & & & .08 & .45 & .38 \\
\hline 3. Closeness & & & & .92 & .97 \\
\hline 4. Betweenness & & & & & .83 \\
\hline 5. Eigenvector & & & & & \\
\hline Mean & 2.09 & 1.50 & 2.18 & 75.62 & 1.68 \\
\hline Std. deviation & 1.10 & 1.06 & 1.00 & 8.50 & 1.20 \\
\hline
\end{tabular}

The model explains 39\% of variance in the involvement. The expected role $(\beta=.02, \mathrm{p}>.05)$ did not have a significant impact on the individual's involvement. Therefore, hypothesis two is rejected. Hence, those who play leadership roles-giving informal advice to businesses or being expected to participate in decision-making processes - are not necessarily involved in an informal business. Ironically, these 


\section{The Role of Social Capital for Amish Entrepreneurs in Pursuing Informal Economic Opportunities - Sunny Joeng}

local economic leaders may play visible, formal leadership roles, but not for individual cases of business start-ups. On the other hand, betweenness centrality has a negative influence on one's involvement. Its standardized regression coefficient is $1.79(\mathrm{p}<.05)$. Betweenness of advice and decision making roles measures the number of times that one actor falls along the shortest path between two other actors. Actors with high betweenness link together actors who are otherwise unconnected, creating opportunities for exploitation of information and control benefits. Yet, those located most often between two others are the least likely to be involved in an informal tourism business.

Table 3: Summary of Regression Analysis for Hypothesis 2

\begin{tabular}{lll}
\hline & \multicolumn{2}{l}{ Business Involvement } \\
\hline & Standardized $\beta$ & $\mathrm{p}$ \\
Role & .02 & $>.05$ \\
Closeness & 4.27 & $>.05$ \\
Betweenness & -1.79 & $<.05$ \\
Eigenvector & -2.93 & $>.05$ \\
$\mathbf{R}^{2}$ & .39 & \\
\hline
\end{tabular}

\section{The Structural Dimension of Social Capital}

Tie strength: The third hypothesis predicts that tie strength will be positively associated with participation in new business opportunities. I created a friendship relation network matrix for the 22 people on the list by counting frequencies for the following: gone out for coffee together, non-work conversations, emails for chatting, or attendance at a social gathering together. Summed scores were calculated into a tie strength matrix. To deal with possible upward or downward biases in respondents' self-reported data, I used the average of the responses from any pair of actors involved in a relationship (Borgatti, Everett, and Freeman 2002). For instance, if person A reported communicating with person B four times a week, and person B reported communicating with person A ten times a week, the average frequency of communication between A and B would be seven. The friendship network and a work network were summed into one aggregate measure of tie strength. Due to different intimacy levels between work and friendship relations, I double weighted friendship relations. Because tie strength is a type of relational data, I transformed the 
involvement variable into a square matrix (Table 4). If a strong tie influences one's involvement in a business, the level of business involvement should be similar among those two actors. People who have strong ties to others who are not involved in a business are least likely to get involved while people who have strong ties to others who have a high level of involvement in a business are more likely to participate in a business opportunity. QAP relational cross tabs analyze whether or not pairs of strong ties show a similar level of involvement than those with weak ties; it was used to test hypothesis 3 . No association was demonstrated between the degree of involvement and tie strength $(\mathrm{p}>.05)$.

Table 4: Cross Tabs Analysis

\begin{tabular}{|lll|}
\hline & \multicolumn{2}{l|}{ Involvement } \\
Tie Strength & 0 & 1 \\
$\mathbf{0}$ & 53 & 107 \\
$\mathbf{1}$ & 25 & 46 \\
\hline
\end{tabular}

Therefore hypothesis three is not supported by the test results. Tie strength does not explain involvement in informal tourism business opportunities. As was expected from previous research of relations between tie strength and the business, new tourism business opportunities often came from weak heterogeneous ties of individuals such as acquaintance of business, work, and events. Most people who were involved in the informal Amish tourism businesses were informed either by indirect ties such as their friends' friend or family's friends, or weak ties such as someone they know by contracts or work a while ago, etc. Interestingly, strong ties which got people involved in new tourism programs were often found as strong diverse ties. For example, an Amish neighborhood where an English family was living nearby was informed of new tourism business opportunities because of their strong ties with their English neighbor. New entrepreneurs appear to acquire more information about a new tourism business opportunity through strong ties that cross boundaries of religion, community, church, gender, and locations. These aspects correspond with the results from testing hypothesis one, which noted the benefit of heterogeneous ties.

Influence of strong social ties on business growth: Strong social capital was effective. It was often pursued by entrepreneurs once the business evolved into the formal sector and/or the entrepreneur needed advice on the growth, stability, and 


\section{The Role of Social Capital for Amish Entrepreneurs in Pursuing Informal Economic Opportunities - Sunny Joeng}

sustainability of business. Advice in more complicated situations comes from one's strong ties.

When we started the bed and breakfast business in Arthur, my daughter did not like the idea and she was against it...well, once we started, family members became great supporters... whenever I need to ask how we are doing, what we should do better, I always ask my daughter first to see what she thinks and she is always there for us (Respondent 10, English, Female, August 8, 2007).

It's all individuals' strong relations with others and there is no link between Amish and English [to get help] (Respondent 18, English, Male, April 17, 2004).

Sunny: The question I asked you before, whether Amish come to you to find information or do you go after Amish to keep your business alive and successful?

Respondent 17: Well, a lot of my information is obtained personally, I guess, through my relationships with my in-laws and that kind of thing....My brother-in-law is Amish, and we've contacted him about doing details of woodworking tours and then I think that's about it (English, Female, July 24, 2007).

Hypothesis four predicts a similar degree of one's involvement among those who are structurally equivalent. The structural equivalence model was highlighted by Burt (1982) who proposed that behavior is predicted better by network position than by interactions with others. The term structural equivalence refers to positions in the network that have the same structural characteristics, for example, each of the individuals who are the most central in their cluster could be structurally equivalent. The assumption behind this hypothesis is that a set of people identically positioned in the flow of communication will use each other as a frame of reference for subjective judgments, and so make similar judgments even if they have no direct communication with each other. In the present case, this means people who are structurally equivalent will have similar degrees of tourism business involvement.

I used CONCOR (CONvergence of iterated CORrelations) to test hypothesis four. CONCOR is a method of partitioning matrix data into blocks (Faust 1988) that compares the pattern of relations for any two actors by correlating the values in each 
cell of the row and column of the network matrix that is associated with each member of the pair. The strength of this method is that it does yield structurally equivalent blocks and a description of the relations between them, which is useful for the interpretation of results.

\section{Figure 1: Partition Diagram: Structural Equivalence}

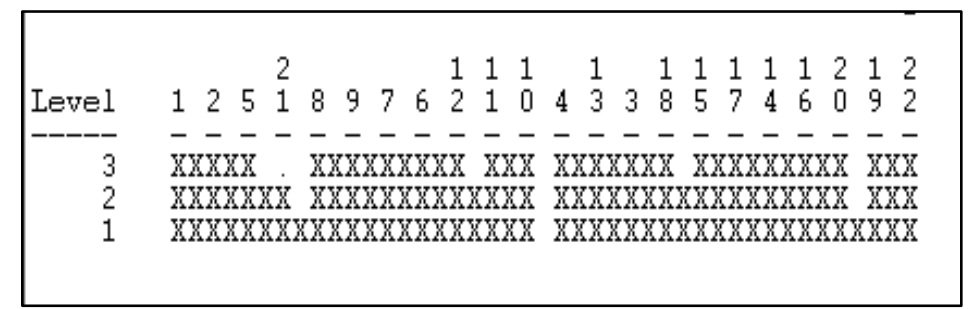

Figure 2: Cluster Diagram: Structural Equivalence

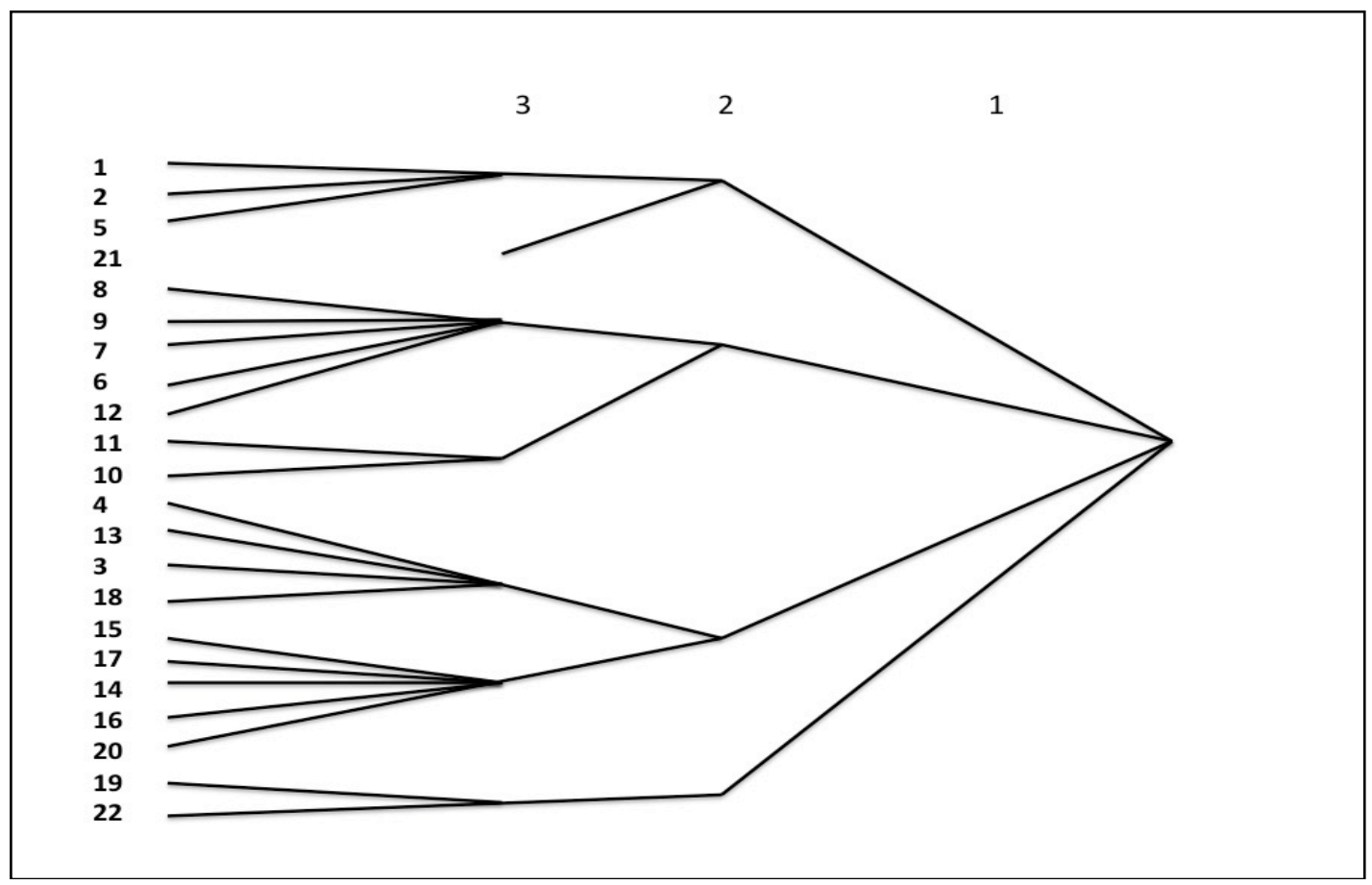

Analysis of structural equivalence helps explain the pattern of relationships in a graph by creating classes or groups of actors who are "equivalent" in one sense or another. Two actors who are structurally equivalent have the same ties to all other actors. They are perfectly substitutable or exchangeable, although it is rare to have pairs of people in reality who are $100 \%$ structurally equivalent. 


\section{The Role of Social Capital for Amish Entrepreneurs in Pursuing Informal Economic Opportunities - Sunny Joeng}

The CONCOR analysis resulted in a three-split (six group) model with an rsquared value of 0.579 . This means that over half of the variance in the ties in the CONCOR model can be accounted for by a "perfect" structural block model.

Although there is no real criterion for a good fit, this is regarded as a relatively great fit. Figures 1 and 2 show the six groups in the three splits. In the first division, the two groups $\{1,2,5,21,8,9,7,6,12,11,10\}$ and $\{4,13,3,18,15,17,14,16,20,19,22\}$ were formed. On the third split these were sub-divided into $\{1,2,5\},\{21\},\{8,9,7,6$, $12,11,10\},\{4,13,3,18\},\{15,17,14,16,20\}$, and $\{19,22\}$. Actors in the same block are approximately structurally equivalent. The block model also provides a description of what it means when we say "the actors in block one are approximately structurally equivalent." The data matrix (Figure 3) representing the social network is partitioned into a set of blocks. Each block consists of a group of individuals who have patterns of relations to others that are more similar to members of their block than to members of other blocks.

Figure 3: Data Matrix - Concur Analysis

\begin{tabular}{|c|c|c|c|c|c|c|c|c|c|c|c|c|c|c|c|c|c|c|c|c|c|c|}
\hline & 1 & 2 & 5 & 21 & 8 & 9 & 7 & 6 & 12 & 11 & 10 & 19 & 22 & 3 & 13 & 4 & 18 & 15 & 14 & 20 & 16 & 17 \\
\hline 1 & & 6 & 3 & 2 & 5 & 5 & 5 & 5 & 4 & 3 & 2 & 2 & 2 & 4 & 5 & 4 & 5 & & 5 & 5 & 4 & 5 \\
\hline 2 & 6 & & 1 & & 6 & 4 & 4 & 4 & 2 & & & & & 5 & 5 & 3 & 5 & 5 & 5 & 5 & 4 & 5 \\
\hline 5 & 3 & 1 & & 1 & 6 & 4 & 5 & 5 & 2 & 3 & 3 & 2 & 1 & 6 & 4 & 4 & 4 & 4 & 4 & 6 & 4 & 2 \\
\hline 21 & 2 & & 1 & 3 & 3 & 3 & 4 & 3 & 3 & & 1 & 3 & 3 & 1 & 3 & 1 & 2 & 3 & 3 & 2 & 3 & 3 \\
\hline 8 & 5 & 6 & 6 & 3 & & 5 & 5 & 5 & 3 & 3 & 3 & & & 3 & & & 2 & & & & & \\
\hline 9 & 5 & 4 & 4 & 3 & 5 & & 5 & 1 & & 3 & 3 & & 3 & & & & 3 & & & & & \\
\hline 7 & 5 & 4 & 5 & 4 & 5 & 5 & & 4 & 3 & 3 & 5 & 2 & 3 & 5 & & & 2 & & & 1 & 1 & \\
\hline 6 & 5 & 4 & 5 & 3 & 5 & 1 & 4 & & 5 & 3 & 2 & 2 & 1 & 3 & 1 & 2 & 1 & 1 & 1 & 1 & 1 & 1 \\
\hline 12 & 4 & 2 & 2 & 3 & 3 & & 3 & 5 & & & 1 & 2 & 2 & 3 & 1 & 2 & 2 & 1 & & 2 & & \\
\hline 11 & 3 & & 3 & & 3 & 3 & 3 & 3 & & & 3 & & 3 & & & & & 3 & & 3 & & \\
\hline 10 & 2 & & 3 & 1 & 3 & 3 & 4 & 2 & 1 & 3 & & 5 & 4 & 3 & 1 & 2 & 1 & 1 & 1 & 1 & 2 & 1 \\
\hline 19 & 2 & & 2 & 3 & & & 2 & 2 & 2 & & 5 & & 3 & 3 & 1 & 3 & 2 & 2 & & 5 & 2 & 2 \\
\hline 22 & 2 & & 1 & 3 & & 3 & 3 & 1 & 2 & 3 & 4 & 3 & & 3 & 3 & 2 & 4 & & 2 & 3 & 3 & 3 \\
\hline 3 & 4 & 5 & 6 & 1 & 3 & & 5 & 3 & 3 & & 3 & 3 & 3 & & 4 & 3 & 3 & 4 & 4 & 4 & 3 & 2 \\
\hline 13 & 5 & 5 & 4 & 3 & & & & 1 & 1 & & 1 & 1 & 3 & 4 & 2 & 4 & 3 & 3 & 3 & 3 & 3 & 4 \\
\hline 4 & 4 & 3 & 4 & 1 & & & & 2 & 2 & & 2 & 3 & 2 & 3 & 4 & & 2 & 2 & 2 & 3 & 2 & 2 \\
\hline 18 & 5 & 5 & 4 & 2 & 2 & 3 & 2 & 1 & 2 & & 1 & 2 & 4 & 3 & 3 & 2 & & 2 & 2 & 2 & 6 & 2 \\
\hline 15 & & 5 & 4 & 3 & & & & 1 & 1 & 3 & 1 & 2 & & 4 & 3 & 2 & 2 & & & 2 & & \\
\hline 14 & 5 & 5 & 4 & 3 & & & & 1 & & & 1 & & 2 & 4 & 3 & 2 & 2 & & & 2 & & \\
\hline 20 & 5 & 5 & 6 & 2 & & & 1 & 1 & 2 & 3 & 1 & 5 & 3 & 4 & 3 & 3 & 2 & 2 & 2 & 5 & 2 & 2 \\
\hline 16 & 4 & 4 & 4 & 3 & & & 1 & 1 & & & 2 & 2 & 3 & 3 & 3 & 2 & 6 & & & 2 & & \\
\hline 17 & 5 & 5 & 2 & 3 & & & & 1 & & & 1 & 2 & 3 & 2 & 4 & 2 & 2 & & & 2 & & \\
\hline
\end{tabular}

Based on the block model and identified classes, I created a new binary matrix of structural equivalence. For example, actors one, two, and five (class one) are tied together and assigned a value one, since they are structurally equivalent. Therefore, links do not identify any direct relation, but indicate a structural equivalence from one to the other. The hypothesis was tested by using two crosstab analyses between the 
structural equivalent matrix and involvement (Table 5). Hypothesis four is not supported by the results. No association was demonstrated between the degree of involvement and structural equivalence in the communication network $(p>.05)$.

Figure 4: Block Image Matrix of CONCUR Results

\begin{tabular}{l|lllllll} 
& $\mathbf{1}$ & $\mathbf{2}$ & $\mathbf{3}$ & $\mathbf{4}$ & $\mathbf{5}$ & $\mathbf{6}$ & $\mathbf{7}$ \\
\hline $\mathbf{1}$ & 1 & & & & & & \\
$\mathbf{2}$ & 0 & 0 & & & & & \\
$\mathbf{3}$ & 1 & 1 & 1 & & & & \\
$\mathbf{4}$ & 0 & 0 & 1 & 1 & & & \\
$\mathbf{5}$ & 0 & 1 & 0 & 1 & 1 & & \\
$\mathbf{6}$ & 1 & 0 & 0 & 0 & 1 & 1 & \\
$\mathbf{7}$ & 1 & 1 & 0 & 0 & 0 & 1 & 0
\end{tabular}

Figure 5: Connection between Groups
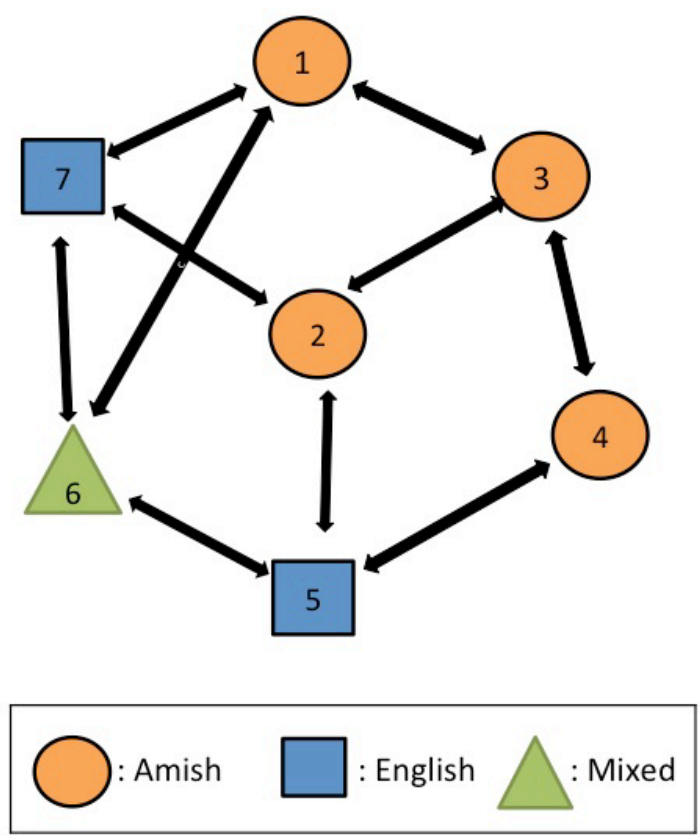

Partitioning by the CONCOR method yields a density matrix reflecting the density of ties (density is the number of observed ties versus the number of possible ties) within and between each block. The next step in block modeling is to recode the density matrix to reflect the generalized from/to connections between and among members of blocks as a pattern of zeros and ones, the image matrix for the structural equivalence model. There are several coding methods that can be used. I used the 


\section{The Role of Social Capital for Amish Entrepreneurs in Pursuing Informal Economic Opportunities - Sunny Joeng}

alpha criterion, coding every cell with a density greater than or equal to the overall density of the observed data matrix $(\alpha)$ as one. The image matrix (Figure 4 ) is used to create a diagram representing all of the to/from relationships between actors, based on their structural equivalence block membership. In this model, actors in equivalence class one are likely to have ties to all actors in blocks three and six. Actors in equivalence class two are likely to be linked to all actors in blocks three, six, and seven. So, I have not only identified the classes, I have also described the form of the relations that makes the cases equivalent. Actors in block six have communication with actors in block seven at slightly more than the average rate of communication in the original data matrix ( $\alpha=2.27)$, while the density of ties within blocks one and six were more than twice that of $\alpha$. Also, interestingly, any actors in blocks (group) three and four (all English) were not connected to the Amish groups.

Structural equivalence analysis often produces interesting and revealing findings about the patterns of ties and connections among the individual actors in a network. The structural equivalence concept aims to operationalize the notion that actors may have identical or nearly identical positions in a network and hence be directly "substitutable" for one another. An alternative interpretation is that actors who are structurally equivalent face nearly the same matrix of constraints and opportunities in their social relationships.

\section{Figure 6: Structurally Equivalent Groups within Communication Networks}

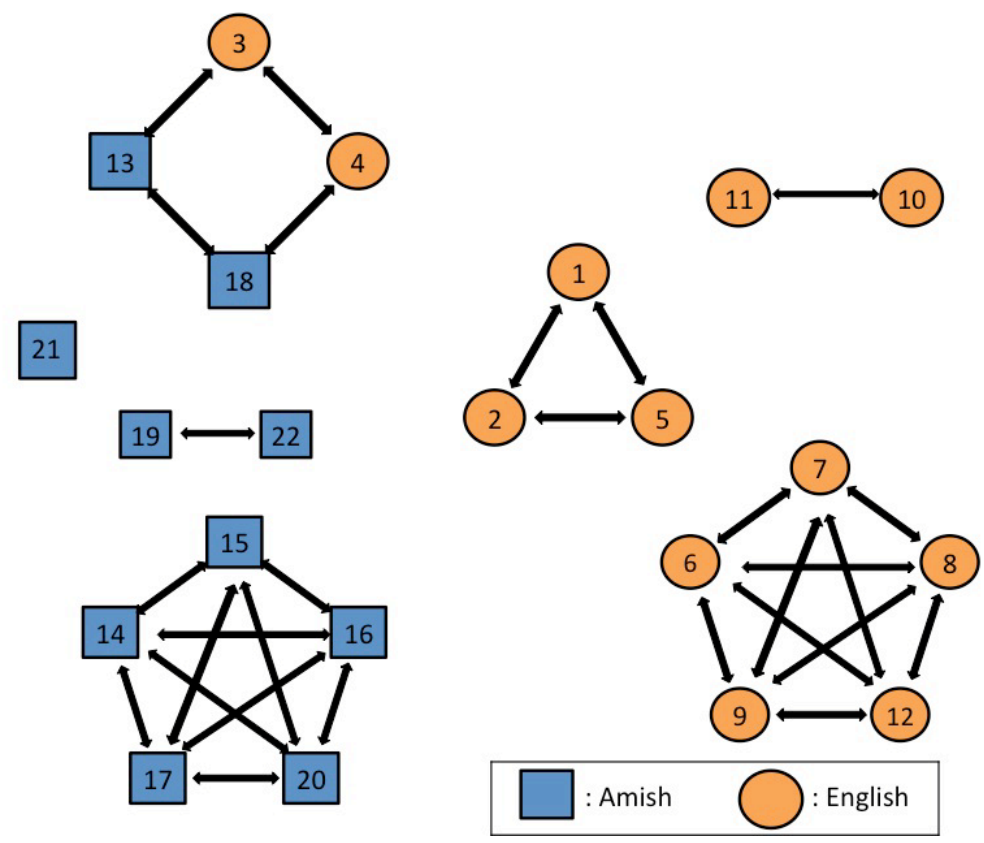


Sociological analysis is not really about individual people. Structural analysis is primarily concerned with the more general and abstract idea of the roles or positions that define the structure of the group, rather than the locations of specific actors with regard to specific others. Although people holding similar structural positions in the Amish informal tourism business network did not show a similar degree of involvement in the development, simplified structural pattern like Figures 5 and 6 can help the visualization of their communication structure and where to change to build a better information and resource flow channel.

\section{Summary of Main Findings}

This study investigates the impact of relational ties on individuals' involvement in informal businesses, that is, how informal business operators got involved and sustain their activities. It used the development of tourist businesses in the large Amish community of Arthur, Illinois, to examine the role of social capital in local economic development.

First, social capital's benefits were not gained through homogeneous close relations but by heterogeneous ties. However, tie strength combined with diverse relations gives a different perspective of social capital's cognitive dimension. In social capital research, diverse ties are typically considered weak ties. Yet, the major informal tourism business opportunities that Amish people pursued came from strong diverse ties in the community, not weak diverse ties.

Building relations beyond one's own close relations are important to build social capital. At the same time, developing constant and strong relations with new diverse ties are as important as building new relations. The combined effects of diversity and strength of ties should be further examined. We should not assume that a diversity of weak ties is not beneficial or that strong diverse ties are always possible. It may work in rural communities like those of the Amish where building new diverse ties are limited. In that case, reaching out to new people via one's socio-demographic boundaries of family, work, church, and gender might be a good strategy. Meeting new people from a church (building a new tie based on potential strong relation) might be an example. For Amish to meet English (crossing ethnicity boundary) on a one-on-one basis or through neighbors and friends, but still guarding strong and consistent ties in the same religious activities, can possibly bring more opportunities in the informal economy than meeting English in larger and more formal community settings. In any case, we should not conclude homogeneous ties are negatively related to business opportunity identification and participation but rather understand that 


\section{The Role of Social Capital for Amish Entrepreneurs in Pursuing Informal Economic Opportunities - Sunny Joeng}

strong heterogeneous relations are more fruitful for engaging informal business opportunity.

Second, I found that people who play leadership roles advising informal businesses or being expected to participate in decision-making processes are not necessarily involved in the businesses. In addition, high betweenness centrality of the advice and decision making roles are negatively related to involvement in informal business. The more a person serves as a network bridge, the less likely he or she is involved in an informal business opportunity. Persons who serve as brokers between the role expectation networks (most likely the English and Amish communities) are typically not involved in a tourism business. One likely possibility is that people who are already involved in tourism businesses expect advice and information not from "competitors" but from those who have no conflict of interest, that is, those outside the business circle to which they belong. This is a point worth further investigation. Crossing boundaries of religion, community, church, gender, and locations seems to work better with strong ties in order for the new entrepreneur to be informed and to initiate new tourism business opportunities. These aspects will be more discussed in the result of testing hypothesis four.

\section{Additional Findings}

\section{Influence of gender}

Although I was not investigating the effect of gender, I did observe some impact serendipitously. Gender seems to play a significant role for the tourism businesses in this area since five tourism agents representing each town as a director of the information/visitor center are all women. Male business owners or tourism business managers expressed their animosity by referring to them as "tourism girls" or "a couple of ladies who think they know everything," The current Convention Visitor Bureau (CVB) was formerly the tourism bureaus of Douglas County and Moultrie County before four women representing various towns in the counties got together to start the CVB.

They think they are CVB but they are not...A couple of ladies who like to go out for having a lunch once a month...I don't talk to them anymore. CVB should not focus on the bus tour.... Current niche market is a small size of group or family travelers...CVB does not help at all for small business owner like me... (Respondent 6, Downtown Merchant, English, Male, September 11, 2007) 
Journal of Amish and Plain Anabaptist Studies, Volume 1, Issue 1 (April), 2013

Despite the dominant roles of women in tourism businesses, often tourism jobs are considered part-time or as a source of additional income carried out by women.

Occasionally Mervin will help Verna serve. She does all the cooking and sometimes he'll just...if she doesn't have enough help in the kitchen he'll come in and serve the meals. And Vic will do the same if he's there, which he's not there for noon meals and we have a lot of noon meals. But like Marie has all women. Lorena... I've not actually been to a meal at her house. I know it's sad to say. But her sons do help her. It is female dominant and it is women's work. (Respondent 3, English, Female, September 29, 2007)

Sunny: Does this help for your household income?

Respondent 15: Well...I guess...I do serving meals and working with visitors on top of all other house works... While my husband farms or runs the shop, I cook, clean, sew, and care for the family, as well as maintain a huge garden, taking care of the chickens, milking the cows, or filling in at the shop when necessary. So, it's part time job for me.

(Amish, Female, July 25, 2007)

Many Amish shops do incorporate the wives into the business by choosing a name that combines the husband's and wife's initials, such as J. \& F. (Jake and Fanny), F. \& B. (Freeman and Bertha), M. \& E. (Marvin and Elnora), etc.

Amish women are very much like entrepreneurs...But they are not vocal with men around (Respondent 9, English, Female, October 1, 2007; Respondent 4 and Respondent 8, both English and male, made very similar statements)

[The husband] who is working at [name] woodworking set an appointment with me not letting [his wife] know that I am coming. In the middle of the talk, she came in with a very suspicious look and uncomfortable face (she was folding her laundry and was around when I asked him a couple more question). She peeped but never talked...this was often the case for a lot of other families...usually guys talk and women sit nearby or do her work...Women were often invisible, submerged, or hidden (From author's field notes, September 30, 2007) . 


\section{The Role of Social Capital for Amish Entrepreneurs in Pursuing Informal Economic Opportunities - Sunny Joeng}

As such, women in a rural area are more prone to try a new business opportunity and get men into the business later. The hospitality business is considered feminine, so men's roles are limited to assistance.

\section{The role of evolving social capital}

While this study examined the existing social capital of individuals and its impact on involvement, I also observed the evolving nature of social capital. Informal tourism business programs and relations built between English and Amish communities functioned to bring communities and visitors together and strengthened their latent social capital. In other words, informal business opportunities brought by social capital create other opportunities to develop new networks or relations. Here are examples:

Using the network built by tourism, the Center is in a better position to contact and invite the Amish to the Center to provide educational opportunities. (Respondent 18, English, Male, August 4, 2007)

Respondent 17: Ideally we would like for more Amish people to come to the Center and learn about their history. I'm not sure if you're familiar...We had the Mirror of the Martyrs exhibit from Kansas brought in. The exhibit focuses on Amish and Anabaptist history. And, so we had a lot of Amish people come to that. (English, Female, July 24, 2007)

Sunny: In the special exhibit room?

Respondent 17: Um-hmm, in the changing exhibit area. And we also...for a week we had it at the Otto Center in Arthur. We hosted it over there. And, we had 300 Amish school children come through, and because they had gone through they came home and told their parents about it, and so we had a symposium with it. And a lot of Amish people came to that. And so the Amish don't come here... I would say just maybe a handful, maybe a dozen a month at best, to go through the museum and that kind of thing. But, when we have special events like that they really appreciate it. Because the community is becoming so far removed from their roots, they want to educate their children about their history...because a lot of what they do today... almost all of what they do today is based on their history. So, it is important for some families. And some families...they just continue doing the things they do because 
that's how their parents did it (laughter). They don't learn about it. I can't really blame them either because I don't know that much about my family history either (laughter). (English, Female, July 24, 2007)

Because the Center built social capital through informal business opportunities, the Amish came to view the special exhibits in the Center. These extended interactions created a space for both communities to learn and teach each other. It helped build social capital to foster more collaboration and involvement. More importantly, social capital built with visitors helped sustain community involvement. Positive experiences with visitors confirmed local Amish residents' continuous involvement in tourism businesses. A great portion of the benefit and enjoyment expressed by participants came from direct contact with visitors. These contacts were made possible partly due to informal business settings, inviting strangers into one's homes to serve meals and chat. Likewise, it resulted in the sustainable participation of the locals in the informal Amish tour program business.

I enjoyed tremendously meeting with new people. It was a great learning experience for my whole family, too...I stopped hosting people because of the lack of hands at that time, but I would really like to start again. We don't have to travel to meet all those people from all over the world. They are from all different countries. (Respondent 12, Amish, Male, September 20, 2007)

I liked to meet with new people, and it has been very fun to meet people from all over the world... (Respondent 20, Amish, Male, July 21, 207)

I made a lot of friends...Especially, when one lady is asking me about this idea, pen pal...she was looking for someone she can write a letter to... I said I would try...It turned out to be a blessing to me... we have exchanged lots of letters and gifts over three years now. One time, she visited me and stayed here...I would love to go visit her sometime too... (Respondent 14, Amish, Female, July 25, 2007)

You know...making good friends got me connected to the outside world, and I am experiencing the world through them... and I figured 'ah...they are the same like us. (Respondent 19, Amish, Male, July 24, 2007)

I am learning new things all the time from visitors...I am enjoying it so much...I might ask them questions as much as they ask me questions.

(Respondent 21, Amish, Female, July 24, 2007) 


\section{The Role of Social Capital for Amish Entrepreneurs in Pursuing Informal Economic Opportunities - Sunny Joeng}

More attention to the evolving nature of social capital in the informal sector should be given. Existing social ties explains one's involvement in informal business. At the same time, informal settings to foster natural interactions among participants in the informal sector create an environment to build new social capital

\section{Conclusion}

This paper investigates how the actors' involvement in the informal economy is determined by the social networks in which one's social life is embedded. Personal relations alone do not directly grant access to informal business opportunities, but rather relationship attributes activate ties that grant access to business development resources. This study addresses the limitations and ambiguities in using social capital as an independent explanatory variable, whereby relations and abilities to activate resources are not differentiated. Thereby, I developed a comprehensive framework extending the theory of social capital, differentiating resources, relations, and the nature of relations. The social capital framework encompassed three dimensions of social capital - the cognitive dimension, the reciprocal dimension, and the structural dimension — and provided a range of possible systematic measures of social capital in entrepreneurship.

I conducted exploratory research in a small rural Amish community in Illinois to test four hypotheses about social capital and its relation to one's involvement in the informal economy. This study measured relational homogeneity within a common culture and religion, tie strength, expected role in one's network, and structural equivalence. Findings indicated that neither tie strength nor diversity of ties alone explained one's involvement in the informal economy. Rather, a combination of strong and diverse ties was positively related to the involvement and success of one's involvement in the informal sector. Therefore, this study calls for expanded consideration of both tie strength and diversity.

On the other hand, the findings suggest the importance of network ecology as a research domain of social capital and entrepreneurship. While this study examined the existing social capital of individuals and its impact on the involvement, it also found that informal tourism business programs functioned to bring communities and visitors together. Their positive interactions among participants helped to build social capital to ensure future involvement. As such, the dynamics of network change over time through which networks and other social entities related to the development of informal businesses co-evolve suggests new directions for research in this area. 
Journal of Amish and Plain Anabaptist Studies, Volume 1, Issue 1 (April), 2013

\section{Endnotes}

${ }^{1}$ Contact information: Sunny Jeong, Ph.D., Assistant Professor, Department of Business, Wittenberg University, Ward Street at North Wittenberg Avenue, Springfield, Ohio 45501-0720. jeongs@wittenberg.edu

${ }^{2}$ From an interview with Theresa, director of the Amish Visitors Center.

${ }^{3}$ That is, those who are not members of the plain Anabaptist community. This terms is used by the Amish.

${ }^{4}$ Closeness centrality measures the sum of the geodesic distances (shortest path between actors) from each actor to all others (farness). Actors with high closeness centrality are considered central in a social network as their distance to other actors is short. Betweenness centrality quantifies the number of times a node acts as a bridge along the shortest path between two other nodes. Actors with high betweenness centrality are in a favored position to the extent that the actors fall on the geodesic paths between other pairs of actors in the network (they can control information flow). Both betweenness and closeness centrality are claimed to be important for the effectiveness of someone's network position. 


\section{The Role of Social Capital for Amish Entrepreneurs in Pursuing Informal Economic Opportunities - Sunny Joeng}

\section{References}

Arrow, Kenneth J. 1974. The Limits of Organization. New York: W.W. Norton \& Company.

Barnes, John Arundel. 1972. Social Networks. Reading, MA: Addison-Wesley.

Barringer, Bruce, and Duane Ireland. 2007. Entrepreneurship: Successfully Launching New Venture. Upper Saddle River, NJ: Prentice Hall.

Bidddle, Bruce. J. , and Edwin.J. Thomas. 1966. Role Theory: Concepts and Research. New York: Wiley.

Borgatti, Steven. P. , Martin. G. Everett, and Linton. C. Freeman. 2002. UCINET VI. Natick, MA: Analytic Technologies.

Bott, Elizabeth. 1971. Family and Social Network. London: Tavistock.

Bourdieu, Pierre (Ed.). 1985. The Forms of Capital. New York: Greenwood.

Boxman, Ed. A. W., Paul. M. De Grant, and Hendrik. D. Flap. 1991. "The Impact of Social and Human Capital on the Income Attainment of Dutch Managers." Social Networks 13:51-73.

Boynton, Linda Louise. 1986. "The Effect of Tourism on Amish Quilting Design." Annals of Tourism Research 13(3):451-65.

Buck, Roy. C. . 1978. "Boundary Maintenance Revisited: Tourist Experience in an Old Order Amish Community." Rural Sociology 43(2):221-34.

Buck, Roy. C., and T. Alleman. 1979. "Tourist Enterprise Concentration and Old Order Amish Survival: Explorations in Productive Coexistence." Journal of Travel Research 18(1):15-20.

Burt, Ronald. S. 1992. Structural Holes: The Social Structure of Competition. Cambridge, MA: Harvard University Press.

Burt, Ronald.S. 1978. "Cohesion Versus Structural Equivalence as a Basis for Network Subgroups." Sociological Methods and Research 7(2):189-212. 
Journal of Amish and Plain Anabaptist Studies, Volume 1, Issue 1 (April), 2013

Castle, Emery. N. 2002. A Primer on Rural Community Sustainability. Corvallis, OR: Oregon State University Extension Service

Charmaz, Kathy. 2003. "Grounded Theory " Pp. 81-110 in Qualitative Psychology: A Practical Guide to Research Methods., edited by Jonathan. A. Smith. London: Sage.

Cicourel, Aaron.Victor. 1973. Cognitive Sociology. New York: Free Press

Cobb, Marcia. 1988. "Influence and Exchange Networks among Tourism Oriented Businesses in Four Michigan Communities." East Lansing, MI: Michigan State University.

Coleman, James. S. 1990. Foundations of Social Theory. Cambridge, MA: The Belknap Press of Harvard University Press.

Corman, Steven. 1996. "What's Social Network Analysis?"

de Clercq, Dirk, and Pia Arenius. 2006. "The Role of Knowledge in Business Start-up Activity." International Small Business Journal 24(4):339-58.

Donnermeyer, Joseph, Cory Anderson, and Elizabeth Cooksey. 2012. "The Amish Population: County Estimates and Settlement Patterns." Presentad at the Annual Meeting of the Rural Sociological Association. Chicago.

Faust, Katherine. 1988. "Comparison of Methods for Positional Analysis: Structural and General Equivalences." Social Networks 10(4):313-41.

Feld, Scott. L. 1984. "The Structured Use of Personal Associates." Social Forces 62:640-52.

Friedkin, Noah. E. 1998. A Structural Theory of Social Influence. New York: Cambridge University Press.

Gallin, Dan. 2001. "Propositions on Trade Unions and Informal Employment in Time of Globalization." Antipode 19(4):531-49.

Glaser, Barney G., and Anselm Strauss. 1967. The Discovery of Grounded Theory. . Chicago: Aldine.

Granovetter, Mark. 1973. "The Strength of Weak Ties." American Journal of Sociology 78:1360-80. 


\section{The Role of Social Capital for Amish Entrepreneurs in Pursuing Informal Economic Opportunities - Sunny Joeng}

Granovetter, Mark. 1985. "Economic Action and Social Structure: The Problems of Embedded Ness." American Journal of Sociology 91(11):481-510.

Greene, Jennifer C., Lehn Benjamin, and Leslie Goodyear. 2001. "The Merits of Mixing Methods in Evaluation." Evaluation 7(1):25-44.

Greene, Jennifer. C., Valerie J. Caracelli, and Wendy.F. Graham. 1989. "Toward a Conceptual Framework for Mixed-Method Evaluation Designs." Educational Evaluation and Policy Analysis 11:255-74.

Hakansson, Hakan, and Ivan. Snehota. 1995. Developing Relationships in Business Networks. London: Routledge.

Hamel, Gary., Yves. L. Doz, and C.K. Prahalad. 1989. "Collaborate with Your Competitors and Win." Harvard Business Review 61:133-39.

Hawley, Jana M., and Jean A. Hamilton. 1996. "Retail Entrepreneurial Values in a Bicultural Community: Cultural and Economic Contentions and Negotiation." Journal of Socio-Economics 25(6):639-61.

Heck, Ramona. K.Z., Alma. J. Owen, and Barbara. R. Rowe. 1995. Home-based Employment and Family Life. Westport, CT: Auburn House.

Hemingway, John. L. 1999. "Leisure, Social Capital and Democratic Citizenship." Journal of Leisure Research 31(2):150-65.

Hills, Gerald., Tom Lumpkin, and Robert Singh. 1997. "Opportunity Recognition: Perceptions and Behaviors of Entrepreneurs." Frontiers of Entrepreneurship Research 17:168-82.

Jeong, Sunny. 2008. "Collective Production of Public Goods in Online Travel Communities." Information Technology \& Tourism 10(4):353-73.

Kingsley, Gordon, and Edward J. Malecki. 2004. "Networking for Competitiveness." Small Business Economics 23(1):71-84.

Korunka, Christian, Alexander Kessler, Hermann Frank, and Manfred Lueger. 2010. "Personal Characteristics, Resources, and Environment as Predictors of Business Survival." Journal of Occupational and Organizational Psychology 83(4):1025. 
Journal of Amish and Plain Anabaptist Studies, Volume 1, Issue 1 (April), 2013

Kraybill, Donald, Steve Nolt, and Eric. J. Wesner. 2011. "Sources of Enterprise Success in Amish Communities." Journal of Enterprising Communities: People and Places in the Global Economy 5(2):112-30.

Light, Ivan, and Edna Bonacich. 1988. Immigrant Entrepreneurs: Koreans in Los Angeles, 1965-1982. Berkeley: University of California Press.

Lin, Nan. 2001a. "Social Resources and Instrumental Action." in Social Capital: Theory and Research edited by Nan Lin, Karen Cook, and Ronald S. Burt. New York: Aldine Transaction.

Lin, Nan. 2001b. "Building a Network Theory of Social Capital." in Social Capital: Theory and Research, edited by Nan Lin, Karen Cook, and Ronald S. Burt. New York: Aldine de Gruyter.

Mark, Melvin M., Irwin Feller, and Scott B. Button. 1997. "Integrating Qualitative Methods in a Predominantly Quantitative Evaluation: A Case Study and Some Reflections." Pp. 47-59 in Advances in Mixed-Method Evaluation: The Challenges And Benefits of Integrating Diverse Paradigms, edited by Jennifer C. Greene and Varleri J. Caracelli. San Francisco, CA: Jossey-Bass.

Marsden, Peter V. 1987. "Core Discussion Networks of Americans." American Sociological Review 52:122-313.

Marsden, Peter V. 1988. "Homogeneity in Confiding Relations." Social Networks 10:57-76.

Marsden, Peter V., and K.E. Campbell. 1984. "Measuring Tie Strength." Social Forces 63:482-501.

Marsden, Peter V., and Nan. Lin (Eds.). 1982. Social Structure and Network Analysis. Beverly Hills, CA: Sage.

Marx, John H., and S.L. Spray. 1972. "Psychotherapeutic "Birds of a Feather": Social Class Status and Religio-Cultural Value Homophily in the Mental Health Field." Journal of Health and Social Behavior 13:413-28.

McAdam, Maura, and Susan Marlow. 2007. "Building Futures or Stealing Secrets? Entrepreneurial Cooperation and Conflict within Business Incubator." International Small Business Journal 25(4):361-82. 


\section{The Role of Social Capital for Amish Entrepreneurs in Pursuing Informal Economic Opportunities - Sunny Joeng}

McGrath, Rita G. 1996. "Options and the Entrepreneur: Toward a Strategic Theory of Entrepreneurial Wealth Creation." Academy of Management Proceedings \& Membership Directory 96:101-05.

Merton, R. 1968. Social Theory and Social Structure. . New York: Free Press.

Michener, H. Andrew. 2004. Social Psychology. Wadsworth: Toronto.

Miller, Nancy J. 2001. "Contributions of Social Capital Theory n Predicting Rural Community in Shopping Behavior." Journal of Socio-Economics 30:475-93.

Mitchell, J.C. 1969. "The Concept and Use of Social Networks." In Social Networks in Urban Situations, edited by J.C. Mitchell. Manchester: University of Manchester Press.

Morrill, Calvin, and Gary A. Fine. 1997. "Ethnographic Contributions to Organizational Sociology." Sociological Methods and Research 25:424-51.

Orr, Julian E. 1990. "Sharing Knowledge, Celebrating Identity: War Stories and Community Memory in a Service Culture." in Collective Remembering: Memory in Society, edited by D.S. Middleton and D. Edwards. Beverly Hills. CA: Sage Publication.

Ozgen, Eren, and Robert A. Baron. 2007. "Social Sources of Information in Opportunity Recognition: Effects of Mentors, Industry Networks, and Professional Forums." Journal of Business Venturing 22(2):174-92.

Pigg, Kenneth E., and Laura D. Crank. 2004. "Building Community Social Capital: The Potential and Promise of Information and Communications Technologies." The Journal of Community Informatics 1(1):58-73.

Pilkington, Paul. 2002. "For Debate Social Capital and Health: Measuring and Understanding Social Capital at a Local Level Could Help to Tackle Health Inequalities More Effectively." Journal of Public Health Medicine 24(3):15659.

Portes, Alejandro. 1998. "Social Capital: Its Origins and Applications in Modern Sociology." Annual Review of Sociology 24:1-24. 
Journal of Amish and Plain Anabaptist Studies, Volume 1, Issue 1 (April), 2013

Portes, Alejandro. 2000. "The Two Meanings of Social Capital." Sociological Forum 15(1):1-12.

Portes, Alejandro, and John Walton. 1981. Labor, Class and the International System. New York: Academic Press.

Putnam, Robert D. 1995. "Bowling Alone: America's Declining Social Capital." Journal of Democracy 6(1):65-78.

Raijman, Rebeca 2001. "Mexican Immigrants and Informal Self-Employment in Chicago." Human Organization 60(1):47-55.

Ramos-Rodríguez, A., J. Medina-Garrido, J. Lorenzo-Gómez, and J. Ruiz-Navarro. 2010. "What You Know or Who You Know? The Role of Intellectual and Social Capital in Opportunity Recognition." International Small Business Journal 28(6):566.

Reardon, K.M. 1998. "Participatory Action Research as Service Learning." New Directions for Teaching and Learning 73:57-64.

Renoy, Piet, Staffan Ivarsson, Olga van der Wusten-Gritsai, and Emco Meijer. 2004. Underclared Work in an Enlarged Union: An Analysis of Shadow Work-An inDepth Study of Specific Stems. Brussels: European Commission.

Rogers, Everett M., and D. Lawrence Kincaid. 1981. Communication Networks. New York: Free Press.

Schiff, Maurice. 1992. "Social Capital, Labor Mobility, and Welfare." Rationality and Society 4(April):157-75.

Scott, John. 2000. Social Network Analysis: A Handbook. Thousand Oaks, Ca: Sage.

Singh, Robert P., Gerald E. Hills, G. T. Lumpkin, and Ralph C. Hybels. 1999. "The Entrepreneurial Opportunity Recognition Process: Examining the Role of SelfPerceived Alertness and Social Networks." Academy of Management Proceedings \& Membership Directory:G1-G6.

Small Business Council. 2004. Small Business in the Informal Economy: Making the Transition to the Formal Economy. London: Small Business Council.

Strauss, Anselm, and Juliet M. Corbin. 1990. Basics of Qualitative Research: Grounded Theory Procedures and Techniques. Newbury Park: Sage. 


\section{The Role of Social Capital for Amish Entrepreneurs in Pursuing Informal Economic Opportunities - Sunny Joeng}

Taylor, Steven J., and Robert Bogdan. 1998. Introduction to Qualitative Research Methods. New York: John Wiley.

Venkataraman, Sankaran. 1997. "The Distinctive Domain of Entrepreneurship Research: An Editor's Perspective." Pp. 119-38 in Advances in Entrepreneurship, Firm Emergence, and Growth, edited by Jerome Katz and Robert H. Brockhaus. Greenwich, CT: JAI Press.

Wasserman, Stanley, and Katherine Faust. 1994. Social Network Analysis. New York: Cambridge University Press.

Wellman, Barry, and Stephen D. Berkowitz (Eds.). 1988. Social Structure: A Network Approach. Cambridge: Cambridge University Press.

Williams, Colin C. 2008. "Beyond Necessity-Driven Versus Opportunity Driven Entrepreneurship: A Study of Informal Entrepreneurs in England, Russia and Ukraine." Entrepreneurship and Innovation 9(3):157-65.

Williams, Colin C., and Jan Winderbank. 1998. Informal Employment in the Advanced Economies: Implications for Work and Welfare. London: Routledge.

Woolcock, Michael. 2001. "The Place of Social Capital in Understanding Social and Economic Outcomes." Canadian Journal of Policy Research 2(1):11-17. 